\title{
The Antro-pyloric Capsular Movement by Capsule Endoscopy
}

Kyung Min Kim, MD, Joon Seong Lee, MD*, Tae Hee Lee, MD, Won Young Cho, MD, Hyun Gun Kim, MD, Jin-Oh Kim, MD, Joo Young Cho, MD, and Su Jin Hong, MD

Institute for Digestive Research, Digestive Disease Center, Soonchunhyang University College of Medicine, Seoul, Korea

\section{Background/Aims}

Capsule endoscopy (CE) is used for various purposes. The aims of this study were to classify the types of antro-pyloric capsular movement in CE and to investigate the relationship between the types of capsular movement and clinical factors, including gastric emptying time (GET).

\section{Methods}

Out of 103 patients who received CE between January 2004 and July 2006, 82 patients (33 female, mean age of 50.6 years) were retrospectively analyzed for capsular movement; 21 patients were excluded because of the history of medications and previous surgeries. CE images were interpreted by a single investigator in relation to the GET and types of antro-pyloric capsular movement.

\section{Results}

Antro-pyloric capsular movement was classified into four patterns: type 1, large longitudinal to-and-fro movements in the antrum followed by passage through the pylorus without resistance; type 2, after large longitudinal to-and-fro movements, passage through the pylorus with resistance (> 1 minute); type 3, mixed pattern of type 1 and 4; type 4, weak movement. Median GET by CE were 14.1 minutes (range, 1.2-50.1), 21.7 minutes (6.2-154.9), 57.3 minutes (14.9-249.8), and 58.8 minutes (21.0-249.5) for type 1,2,3, and 4, respectively. GET in type 1 and 2 were significantly shorter than that in type 3 and $4(p<0.05)$. Ten diabetic patients presented with type $2(n=5), 3(n=3)$, and $4(n=2)$ patterns, but not with type 1.

\section{Conclusions}

Our results suggest the analysis of capsule movement using CE to be a possible method of evaluating the antro-pyloric movement.

(J Neurogastroenterol Motil 2010;16:172-176)

Key Words

Capsule endoscopy, Gastric emptying, Diabetes mellitus

Received: November 6th, 2009 Accepted: February 8th, 2010

(c) This is an Open Access article distributed under the terms of the Creative Commons Attribution Non-Commercial License (http://creativecommons. org/licenses/by-nc/3.0) which permits unrestricted non-commercial use, distribution, and reproduction in any medium, provided the original work is properly cited.

*Correspondence: Joon Seong Lee, MD Institute for Digestive Research, Digestive Disease Center, Soonchunhyang University College of Medicine, 657 Hannam-dong, Yongsan-gu, Seoul 140-763, Korea

Financial support: None.

Tel: +82-2-709-9691, Fax: +82-2-795-9696, E-mail: drjslee@dreamwiz.com

Conflicts of interest: None. 


\section{Introduction}

Antroduodenal motility has usually been evaluated using various studies like scintigraphy, ultrasonography, ${ }^{13} \mathrm{C}$-gastric emptying breath test, magnetic resonance imaging (MRI), intraluminal pressure recording, and cutaneous electrogastrography. ${ }^{1}$ However, there is no method which would readily detect the direct movements of swallowed gastric contents.

Capsule endoscopy (CE) has recently been introduced as means of endoscopically exploring the entire small intestine. ${ }^{2}$ Since the introduction of $\mathrm{CE}$, the indications for the procedure have expanded to include gastrointestinal bleeding of obscure origin, assessment of Crohn's disease and celiac disease, and surveillance of polyposis syndrome. ${ }^{3-6} \mathrm{CE}$ could also be used to evaluate patients with abdominal pain or diarrhea. ${ }^{7}$ In addition, $\mathrm{CE}$ can be used to evaluate gastric emptying time (GET) and small bowel transit time, although the emptying of the capsule is different to that of meals. ${ }^{8}$ A previous study which analyzed GET and intestinal transit times through images obtained with $\mathrm{CE}$ suggested that $\mathrm{CE}$ was as an effective method for studying gastrointestinal transit times directly with the possibility of greater knowledge on the pathogenesis of various gastrointestinal conditions. ${ }^{8}$ However, the study did not analyze the capsular movement or antral motility pattern itself.

The aims of this study were to classify the types of antro-pyloric capsular movement in $\mathrm{CE}$ and to investigate the relationship between the types of capsular movement and clinical factors, including GET.

\section{Materials and Methods}

We retrospectively reviewed the data of 103 patients who underwent $\mathrm{CE}$ at Soonchunhyang University Hospital between January 2004 and July 2006. Patients who were taking medications known to interfere with gastrointestinal transit time before $\mathrm{CE}(\mathrm{n}=16)$ and patients who had previously undergone partial or total gastrectomy $(n=5)$ were excluded. In total, 82 patients were enrolled and their medical records reviewed. Data parameters included clinical characteristics, preparation method, medications, and laboratory findings. There were 49 men and 33 women with a median age of 51.5 years (range, 15-88).

The indications for $\mathrm{CE}$ were as follows: overt gastrointestinal bleeding $(\mathrm{n}=29)$, unexplained anemia $(\mathrm{n}=5)$, abdominal pain $(n=14)$, diarrhea $(n=3)$, inflammatory bowel disease $(n=4)$, polyposis syndrome $(n=8)$, and general check-up $(n=19)$. Of the 82 patients, 33 were outpatients and 49 underwent $C E$ during ongoing hospitalization. Ten patients had diabetes mellitus (Table 1).

\section{Preparation}

Patients underwent three types of bowel preparation. All 82 patients fasted for more than 12 hours. Then, 11 patients were prepared with $2 \mathrm{~L}$ polyethylene glycol 18 hours before swallowing the capsule, 37 patients were prepared with $90 \mathrm{~mL}$ sodium phosphate given in two divided doses of $45 \mathrm{~mL}$ each on 18 hours and 9 hours before swallowing the capsule, and 34 patients fasted for 12 hours or more with no other preparation.

\section{CE}

$\mathrm{CE}$ was performed with the M2A system (Given Imaging, Yoqneam, Israel). An array of eight sensors was attached to the chest and abdominal wall of the patient, and a belt holding a data recorder with a battery was fastened around his or her waist. The patient was allowed to resume a clear fluid diet 2 hours after swallowing the capsule (a cylindrical shape $11 \mathrm{~mm}$ in diameter, 26 $\mathrm{mm}$ in length, weighing $3.7 \mathrm{~g}$ ). At 8 hours after ingestion, the recorder was disconnected and the sensors removed. The recorded images were then downloaded to a workstation and viewed with RAPID $^{\mathbb{R}}$ software.

\section{Interpretation of CE images}

The video results produced from the data recorded by each capsule were reviewed by a single investigator (Kim KM). GET was defined as the time between the first gastric image and the

Table 1. Baseline Characteristics of Patients

\begin{tabular}{lc}
\hline \multicolumn{1}{c}{$\begin{array}{c}\text { Number of patients } \\
(\mathrm{N}=82)\end{array}$} \\
\hline Male : Female & $49: 33$ \\
Mean age (range) & $50.6 \pm 16.9 \mathrm{yr}(15-88)$ \\
Out patient : In patient & $32: 49$ \\
Indications of capsule endoscopy & \\
Overt gastrointestinal bleeding & 29 \\
Anemia & 5 \\
Abdominal pain & 14 \\
Diarrhea & 3 \\
Inflammatory bowel disease & 4 \\
Polyp & 8 \\
General check up & 19 \\
\hline
\end{tabular}


first duodenal image of the last passage.

The different types of antro-pyloric capsular movement were defined by the pattern of capsular movement at the antrum and the duration of capsule retention at the pylorus. The investigator first reviewed all images of every patient and then reviewed each image at least three times, inspecting images carefully forward and backward. A track display of the capsule was also used to analyze the capsular movement.

\section{Statistical methods}

Statistical analyses were conducted using the SPSS version 12.0 for Windows software (SPSS Inc., Chicago, IL, USA). Quantitative data are summarized as means, medians, and ranges; categorical data are presented as frequencies (percentages). Categorical data were analyzed using the chi-square test and one-way analysis of variance on rank (Dunn's). A p $<0.05$ was

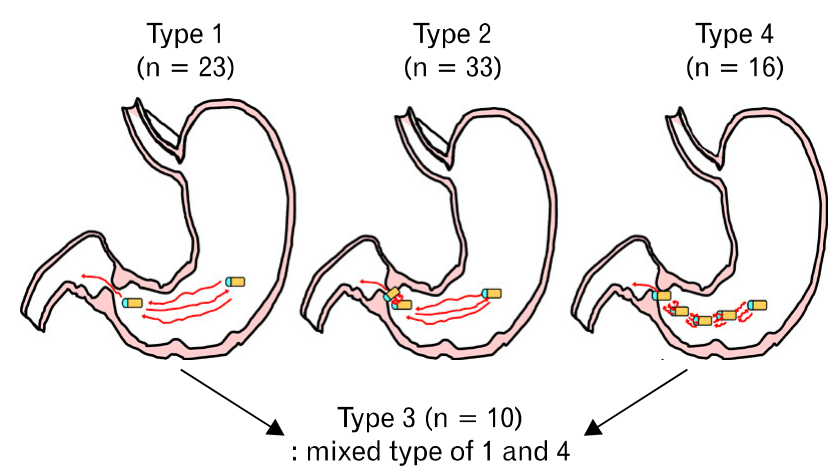

Figure 1. Types of antro-pyloric capsular movement. We classified the antro-pyloric capsular movement into four types. Type 1, broad capsular movement to-and-fro, with strong antral peristaltic contractions, followed by movement to the duodenum without retention at the pylorus. Type 2, broad capsular movement to-and-fro, with strong antral peristaltic contractions, followed by movement to the duodenum with retention at the pylorus. Type 3, mixed pattern of type 1 and 4 . Type 4 , weak capsular movement enabling a particular area to be observed for a prolonged period. deemed statistically significant.

\section{Results}

\section{Types of antro-pyloric capsular movement}

We classified the antro-pyloric capsular movement into four types (Fig. 1): Type $1(\mathrm{n}=23)$, broad capsular movement to-and-fro, with strong antral peristaltic contractions, followed by movement to the duodenum without retention at the pylorus.

Type 2 ( $\mathrm{n}=33$ ), broad capsular movement to-and-fro, with strong antral peristaltic contractions, followed by movement to the duodenum with retention at the pylorus ( 1 minute or more for the capsule to pass the pylorus). Type $3(\mathrm{n}=10)$, mixed pattern of type 1 and 4 . Type $4(n=16)$, weak capsular movement enabling a particular area to be observed for a prolonged period (the same area captured by the capsule was continuously observed for more than 1 minute; images captured when the capsule pivoted around a fixed axis or was in contact with the mucosa were not used to satisfy this criterion).

\section{GET by the types of capsular movement}

There was no retention of the capsule in the stomach in any patient. The median GET in all patients was 25.0 minutes (range, 1.2-249.8). Median GETs by CE were 14.1 minutes (1.2-50.1), 21.7 minutes (6.2-154.9), 57.3 minutes (14.9-249.8), and 58.8 minutes (21.0-249.5) for type 1, 2, 3, and 4, respectively. Notably, GET in type 1 and 2 was significantly shorter than that in type 3 and $4(\mathrm{p}<0.05$, Table 2$)$.

When we arbitrarily considered gastric emptying to be delayed with the pylorus not being reached by 2 hours after the ingestion of capsule, the frequencies of delayed GET were $0 \%$ in type $1,6.1 \%$ in type $2,10 \%$ in type 3 , and $12.5 \%$ in type 4 .

Table 2. Gastric Emptying Time According to the Types of Capsule Movement

\begin{tabular}{lcccc}
\hline Types of capsule movement & Type 1 & Type 2 & Type 3 & Type 4 \\
\hline Number $(\mathrm{N}=82)$ & 23 & 33 & 10 & 16 \\
Number of diabetes $(\mathrm{n}=10)$ & 0 & 5 & 3 & 2 \\
GET, min median (range) & $14.1(1.2-50.1)^{\mathrm{a}}$ & $21.7(6.2-154.9)^{\mathrm{b}}$ & $57.3(14.9-249.8)$ & $58.8(21.0-249.5)$ \\
Delayed GET $(\%)$ & $0(0.0 \%)$ & $2(6.1 \%)$ & $1(10.0 \%)$ & $2(12.5 \%)$ \\
\hline
\end{tabular}

${ }^{\mathrm{a}} \mathrm{p}<0.05$ vs. type 3,4 by one way ANOVA, ${ }^{\mathrm{b}} \mathrm{p}<0.05$ vs. type 4 by one way ANOVA on rank.

GET, gastric emptying time; Delayed GET was arbitrarily defined as GET over $2 \mathrm{hr}$. 


\section{Relationships between capsular movements and cli- nical factors}

Age, gender, and obesity did not significantly affect capsular movement. Furthermore, there was no significant difference in capsular movement with respect to preparation method or whether the patient was admitted or not. Also there was no significant difference in GET with respect to preparation method (Table 3). Diabetic patients showed various types of antro-pyloric movement (Table 2), with the exception of type 1 movement ( $\mathrm{p}=$ 0.053 , diabetic patients with type 1 movement vs. those with type 2,3 , and 4 movement).

\section{Discussion}

There are several methods in evaluating antral motility: gastroduodenal manometry, gastric scintigraphy, real-time MRI, and gastric electrogastrography. ${ }^{1}$ Gastroduodenal manometry is the most reliable method for assessing motility of the antrum to date. However, it is invasive and could only accurately measure the luminal pressure of the distal antrum and prepyloric region when the luminal diameters are less than $5.6 \mathrm{~cm} .{ }^{9}$ Real-time MRI has been proposed for evaluating gastric motility, but data analysis is difficult. ${ }^{10}$ Although dynamic antral scintigraphy reflects the actual motility of the antrum, data analysis is cumbersome, and because the antrum is evaluated in sections, the movements of the antrum may not be properly represented. ${ }^{11}$ Analysis of capsular movement may have several advantages over other techniques: noninvasiveness, no radiation hazard, concomitant diagnosis of any organic disease, and direct detection of fasting movements of gastric contents.

Table 3. Comparison of Gastric Emptying Time Among the Three Different Bowel Preparation Methods

\begin{tabular}{lccc}
\hline \multicolumn{1}{c}{$\begin{array}{c}\text { Methods of } \\
\text { bowel preparation }\end{array}$} & NPO & PEG & $\begin{array}{c}\text { Sodium } \\
\text { phosphate }\end{array}$ \\
\hline $\begin{array}{l}\text { Number } \\
(\mathrm{N}=82)\end{array}$ & 32 & 13 & 37 \\
$\begin{array}{l}\text { Number of diabetes } \\
(\mathrm{n}=10)\end{array}$ & 3 & 3 & 4 \\
$\begin{array}{l}\text { GET, min median } \\
\text { (range) }\end{array}$ & 28.4 & 27.3 & 22.9 \\
$\begin{array}{l}\text { Delayed GET } \\
(\%)\end{array}$ & $3(9.4 \%)$ & $0(0.0 \%)$ & $2(5.4 \%)$ \\
\end{tabular}

NPO, nothing per oral; PEG, polyethylene glycol; GET, gastric emptying time; Delayed GET was arbitrarily defined as GET over $2 \mathrm{hr}$.
Capsular movement in our study was divided into four types. Type 1 reflected strong antral contractions without pyloric resistance; GET was relatively fast. Although type 2 movement showed strong antral contraction, pyloric resistance was increased which resulted in a slower GET. Relatively weak contractions of the antrum were predicted in cases of type 4, and GET was the slowest. Type 3 was a mixed pattern of type 1 and 4 . In this study, diabetic patients showed various types of antro-pyloric movement but none type 1 movement, suggesting decreased antral contractions with increased pyloric resistance. In general, diabetic patients show decreased fundal accommodation, increased diameter of the antrum, weak antral contractions, and increased pyloric spasm or pyloric resistance due to decreased nitric oxide synthase in the pylorus. ${ }^{12,13}$ Our results regarding capsular movements in diabetics support these findings. We believe this to be an internal validation of our categories on the antral capsular movement to some degree.

The antral capsular movement is different from antral food movement since $\mathrm{CE}$ is done in the fasting state. During prolonged fasting, the stomach exhibits several stereotypical contractile patterns known as the migrating motor complex (MMC). Gastric motility that occurs during fasting can be divided into three phases. ${ }^{14}$ The function of MMC phase III is to clear undigestible fibrous materials from the stomach and to move such debris through the small intestine and into the colon. Thus, Gastric emptying by $\mathrm{CE}$ is primarily related to this antral phase III activity in the fasting state. ${ }^{15}$ Phase III movement originates at various sites in the gut, from the distal antrum to the proximal ileum. Although there are variations within and between subjects, around $50 \%$ of phase III movement may start in the stomach. ${ }^{16-18}$ In this study, motility phase was not measured using a manometric system, so we could not determine the effects of antral motility phase on the gastric emptying of capsule. However, we would expect type 1 and 2 movement to be related to the vigorous contractions during MMC phase III, regardless of pyloric resistance, and type 4 movement to be explained with weak contractions in MMC phase II, since a small amount of remnant food may be expelled through the pylorus during MMC phase II. A limitation of this study is in the lack of a reference standard; further study is needed to validate the above hypothesis using both $\mathrm{CE}$ and antropyloroduodenal manometry or dynamic scintigraphy. Another limitation of this retrospective study is with the use of three different preparations for patients, although we found no difference among them. Regarding the issues on the volume of preparation fluid, we did not expect remnant fluid in 
the stomach during $\mathrm{CE}$, because all preparations were done at least 5 hours before swallowing the capsule.

In conclusion, this preliminary study suggests that the analysis of capsule movement using CE might be a possible method of evaluating the antro-pyloric movements. More studies would be needed to develop and establish objective methods to classify and determine the types and characteristics of capsule movement by consensus.

\section{References}

1. Camilleri M, Hasler WL, Parkman HP, Quigley EM, Soffer E. Measurement of gastrointestinal motility in the GI laboratory. Gastroenterology 1998;115:747-762.

2. Iddan G, Meron G, Glukhovsky A, Swain P. Wireless capsule endoscopy. Nature 2000;405:417.

3. Pennazio M, Santucci R, Rondonotti E, et al. Outcome of patients with obscure gastrointestinal bleeding after capsule endoscopy: report of 100 consecutive cases. Gastroenterology 2004;126:643-653.

4. Fireman Z, Mahajna E, Broide E, et al. Diagnosing small bowel Crohn's disease with wireless capsule endoscopy. Gut 2003;52: 390-392.

5. Rondonotti E, Spada C, Cave D, et al. Video capsule enteroscopy in the diagnosis of celiac disease: a multicenter study. Am J Gastroenterol 2007;102:1624-1631.

6. Schulmann K, Hollerbach S, Kraus K, et al. Feasibility and diagnostic utility of video capsule endoscopy for the detection of small bowel polyps in patients with hereditary polyposis syndromes. Am J Gastroenterol 2005;100:27-37.

7. Fry LC, Carey EJ, Shiff AD, et al. The yield of capsule endoscopy in patients with abdominal pain or diarrhea. Endoscopy 2006;38: 498-502.

8. Velayos Jimenez B, Fernandez Salazar L, Aller de la Fuente R, et al.
Study of gastrointestinal transit times with capsule endoscopy. Gastroenterol Hepatol 2005;28:315-320.

9. Fone DR, Akkermans LM, Dent J, Horowitz M, van der Schee EJ. Evaluation of patterns of human antral and pyloric motility with an antral wall motion detector. Am J Pysiol 1990;258:G616-G623.

10. Ajaj W, Goehde SC, Papanikolaou N, et al. Real time high resolution magnetic resonance imaging for the assessment of gastric motility disorders. Gut 2004;53:1256-1261.

11. Urbain JL, Vekemans MC, Parkman H, et al. Dynamic antral scintigraphy to characterize gastric antral motility in functional dyspepsia. J Nucl Med 1995;36:1579-1586.

12. Undeland KA, Hausken T, Aanderud S, Berstad A. Lower postprandial gastric volume response in diabetic patients with vagal neuropathy. Neurogastroenterol Motil 1997;9:19-24.

13. Takahashi $\mathrm{T}$, Nakamura K, Itoh $\mathrm{H}$, Sima AA, Owyang C. Impaired expression of nitric oxide synthase in the gastric myenteric plexus of spontaneously diabetic rats. Gastroenterology 1997;113:535-544.

14. Vantrappen G, Janssens J, Hellemans J, Ghoos Y. The interdigestive motor complex of normal subjects and patients with bacterial overgrowth of the small intestine. J Clin Invest 1977;59:1158-1166.

15. Code CF, Schlegel JF. The gastrointestinal interdigestive housekeeper: motor correlates of the interdigestive myoelectric complex in the dog. In: Daniel EE, ed. Proceedings of the fourth international symposium on gastrointestinal motility. Vancouver: Mitchell, 1974: 631-634.

16. Dooley CP, Di Lorenzo C, Valenzuela JE. Variability of migrating motor complex in humans. Dig Dis Sci 1992;37:723-728.

17. Gregersen H, Rittig S, Vinter-Jensen L, Kraglund K. The relation between antral contractile activity and the duodenal component of the migrating motility complex. Scand J Gastroenterol 1988;152(suppl): 36-41.

18. Rees WD, Malagelada JR, Miller LJ, Go VL. Human interdigestive and postprandial gastrointestinal motor and gastrointestinal hormone patterns. Dig Dis Sci 1982;27:321-329. 